Syntax Fusion : Jurnal Nasional Indonesia

e-ISSN : 2775-4440

Vol. 1, No. 9, September 2021

\title{
ANALISIS PEMAHAMAN PASIEN TERHADAP SISTEM RUJUKAN BERJENJANG PESERTA JAMINAN KESEHATAN NASIONAL (JKN)
}

\section{Donna Elian Saputri dan Yoki Muchsam}

Akademi Perekam Medis dan Informatika Kesehatan (APIKES) Bandung

Email: donnaelians@gmailcom, yoki.muchsam@apikesbandung.ac.id

\begin{abstract}
Abstrak
Penelitian ini bertujuan untuk mengetahui gambaran pemahaman pasien terhadap sistem rujukan berjenjang peserta Jaminan Kesehatan Nasional (JKN). Metode penelitian yang digunakan adalah metode kuantitatif dengan menguji asumsi penelitian dengan perhitungan statistika dengan jenis penelitian deskritif dan teknik pengumpulan data dilakukan dengan cara kuesioner digunakan untuk mendapatkan data dari pasien yang membuat rujukan berjenjang yang ada di puskesmas Parongpong dengan hasil yang tervalidasi oleh aplikasi SPSS tersebut. Dari penelitian yang dilakukan didapatkan hasil adanya ketidakpahaman pasien puskesmas Parongpong terhadap sistem rujukan berjenjang Jaminan Kesehatan Nasional dengan hasil penelitian pemahaman pasien empat indikator yaitu Exemplifying (Memberikan Contoh), Infering (Menyimpulkan), Comparing (Membandingkan), Dan Explaining (Menjelaskan) dinyatakan tidak paham, item atau pernyataan yang dikatakan tidak paham itu mengenai syarat dan prosedur yang didalamnya alur tingkatan Fasilitas Kesehatan Tingkat Lanjutan sekunder maupun tersier. Hal ini terjadi karena kurangnya pemaparan atau promosi kesehatan oleh petugas Kesehatan kepada seluruh pasien peserta JKN yang ada di Puskesmas Parongpong, promosi kesehatan yang dimaksud berupa pembuatan pamflet yang jelas dan efektif.
\end{abstract}

Kata kunci: Pemahaman; Sistem rujukan Berjenjang; JKN

\section{Pendahuluan}

Jaminan Kesehatan Nasional (JKN) merupakan bagian dari Sistem Jaminan Sosial Nasional (SJSN) yang diselenggarakan oleh Badan Penyelenggara Jaminan Sosial (BPJS) Kesehatan melalui mekanisme asuransi kesehatan sosial yang bersifat wajib (UU No 40,2004). Sejak dilaksanakan sistem Jaminan Kesehatan Nasional (JKN) pada 2014, banyak perubahan yang terjadi dalam sistem pelayanan kesehatan di Indonesia. JKN diberikan secara berjenjang yang dimaksud dimana proses tersebut berdasarkan sistem rujukan pelayanan kesehatan adalah penyelenggaraan pelayanan kesehatan yang mengatur pelimpahan tugas dan tanggung jawab pelayanan kesehatan secara timbal balik baik vertikal maupun horizontal (Setiawati \& Nurrizka, 2019).

Suatu sistem rujukan pelayanan kesehatan yaitu rujukan vertikal yang dilakukan antar pelayanan kesehatan yang berbeda tingkatan, dapat dilakukan dari tingkat pelayanan yang lebih rendah ke tingkat pelayanan yang lebih tinggi atau sebaliknya seperti yang dijelaskan pada buku panduan praktis SRB (2014). Sistem rujukan yang 
berjejang terdiri dari fasilitas kesehatan tingkat pertama (FKTP) dan fasilitas kesehatan tingkat lanjutan (FKTL) yang terdiri dari pelayanan kesehatan tingkat kedua (sekunder) dan pelayanan kesehatan tingkat ketiga (tersier) (Faulina, Khoiri, \& Herawati, 2016).

Salah satu jenis fasilitas pelayanan kesehatan tingkat pertama/primer memiliki peranan penting dalam sistem kesehatan nasional, khususnya subsistem upaya kesehatan disebut sebagai Pusat Kesehatan Masyarakat (Puskesmas) dikutip pada Peraturan Kementrian Kesehatan Republik Indonesia (2014). Puskesmas juga merupakan pusat pelayanan kesehatan perorangan pertama dalam pelayanan kesehatan formal Pusat Kesehatan Masyarakat yang dimaksud adalah Puskesmas Parongpong, yang merupakan fasilitas pelayanan kesehatan tingkat pertama pada sistem rujukan berjenjang. Puskesmas ini terletak di daerah kabupaten bandung barat yang membawahi 4 desa dan memiliki wilayah cukup luas serta masyarakat yang padat. Puskesmas tersebut memiliki data jumlah rujukan pada tahun 2020 sebanyak 1.620 pasien dan kemudian peneliti sajikan rata - rata angka rujukan per bulannya di tahun 2020.

Tabel 1 Data Jumlah Rujukan Di Puskesmas Parongpong Pada Tahun 2020

\begin{tabular}{lc}
\hline Rujukan & Pasien \\
\hline Jumlah Rujukan PBI APBN (Jamkesmas) & 430 \\
\hline Jumlah Rujukan PBI APBD (Jamkesda Integrasi) & 76 \\
\hline Jumlah Rujukan Peserta BPJS Mandiri & 893 \\
\hline Jumlah Rujukan Peserta BPJS PNS atau TNI, POLRI (ASKES) & 221 \\
\hline Jumlah & $\mathbf{1 6 2 0}$ \\
\hline Rata-rata Perbulan & $\mathbf{1 3 5}$ \\
\hline
\end{tabular}

Sumber: Data Puskesmas Parongpong tahun 2020

Berdasarkan tabel 1.1 diatas diketahui tingkat rujukan di puskesmas tersebut cukup tinggi. Sementara itu, peneliti melakukan beberapa pengamatan pada saat Praktek Kerja Lapangan (PKL) bahwasannya implementasi suatu sistem tidak akan berjalan baik jika pelaksanaannya tidak sesuai dengan ketentuan kebijakan atau pedomannya. Permasalahan yang bisa datang dalam implementasi sistem rujukan berjenjang adalah bagaimana pemahaman dengan indikator yaitu interpretasi, memberikan contoh, klasifikasi, menyimpulkan, membandingkan dan menjelaskan serta bagaimana kendala dan solusi pada setiap pasien. Contohnya dari hal tersebut adalah permintaan pasien yang menginginkan rujukan dari puskesmas atau pelayanan kesehatan tingkat pertama langsung meminta ke pelayanan kesehatan tingkat lanjutan tersier yang pada dasarnya hal tersebut tidak akan bisa dilakukan.

Sistem rujukan tersebut harus dipahami oleh setiap pelaku, seperti pasien petugas fasilitas tingkat pertama dan tingkat lanjutan, jika salah satu dari para pelaku tidak dapat memahami sistem rujukan tersebut tentunya akan menimbulkan masalah (Muchsam \& Mareta, 2019). Dengan demikian tujuan penelitian ini adalah mengetahui gambaran pemahaman terhadap sistem rujukan berjenjang peserta Jaminan Kesehatan Nasional serta kendala dan solusi pelaksanaannya, kemudian diharapkan penelitian ini bermafaat sebagai pembelajaran, pengembangan ilmu dan perbandingan teori dilapangan mengenai sistem rujukan berjenjang Jaminan Kesehatan Nasional dan BPJS. Serta menjadi bahan 
masukan untuk evaluasi dan solusi bagi Puskesmas Parongpong dalam pemahaman tata cara rujukan. Oleh karena itu, peneliti tertarik untuk melakukan penelitian yang berjudul "Analisis Pemahaman Pasien Terhadap Sistem Rujukan Berjenjang Peserta Jaminan Kesehatan Nasional (JKN)"

Untuk memperjelas uraian pada latar belakang serta teori, maka pemahaman pasien yang merupakan variabel independent terdiri dari Interpreting, Exemplifying, Classification, Infering, Comparing, Explaining yang diduga mempengaruhi atau menjadi perubahannya variabel dependen yaitu Rujukan Berjenjang yang terdiri dari syarat dan prosedur.

\begin{tabular}{|l|l|}
\hline \multicolumn{1}{|c|}{ Pemahaman Pasien } \\
- Interpreting (Interpretasi) \\
- Exemplifying (Memberikan \\
Contoh) \\
- Clasification (Klasifikasi) \\
- Infering (Menyimpulkan) \\
- Comparing \\
(Membandingkan)
\end{tabular}$\quad \begin{gathered} \\
\text { - Explaning (Menjelaskan) }\end{gathered}$

Gambar 1: Kerangka Pemikiran

\section{Hipotesis}

Berdasarkan uraian diatas, maka hipotesis dalam penelitian ini sebagai berikut: $\mathrm{H} 0$ = Adanya ketidakpahaman pasien tentang sistem rujukan berjenjang JKN. $\mathrm{H} 1$ = Adanya pemahaman pasien tentang sistem rujukan berjenjang JKN.

\section{Metode Penelitian}

Metode penelitian yang digunakan dalam penelitian ini adalah metode kuantitatif, metode ini digunakan dengan tujuan untuk menguji asumsi penelitian dengan perhitungan statistika. Metode kuantitatif digunakan oleh peneliti karena untuk memudahkan peneliti menggambarkan hasil penelitian (Silalahi, 2012).

Jenis penelitian ini deskriptif yaitu penelitian yang bertujuan untuk membuat deskriptif atau gambaran secara sistematis, faktual, dan akurat mengenai fakta dan sifat populasi atau daerah tertentu (Neuman, 2013). Variabel yang digunakan adalah pemahaman pasien dan rujukan berjenjang. Populasi pada penelitian ini adalah jumlah klien/ pasien yang dirujuk dari Puskesmas Parongpong dengan rata rata perbulan 135 pasien dirujuk. Teknik pengambilan sampel yang digunakan peneliti adalah pemilihan sampel acak sederhana yang dilakukan dari tanggal 25 Mei sampai dengan 19 Juni 2021. Proses pemilihan sampel dalam cara tertentu yang berarti semua elemen populasi 
didefinisikan mempunyai kesempatan yang sama, bebas dan seimbang dipilih menjadi sampel. Dalam menentukan ukuran sampel dapat menggunakan rumus slovin, yaitu:

Keterangan: $\mathrm{n}=$ Sampel

$$
\mathbf{n}=\frac{N}{1+\left(N \cdot e^{2}\right)}
$$

$$
\begin{aligned}
& \mathrm{N}=\text { Populasi } \\
& \mathrm{e}=\text { Margin of error }
\end{aligned}
$$

$$
\begin{aligned}
\mathbf{n} & =\frac{135}{1+\left(135 \cdot 0.1^{2}\right)} \\
& =57.45=58
\end{aligned}
$$

Teknik pengumpulan data yang digunakan dalam penelitian ini adalah dengan teknik kuesioner yang dibuat dengan menggunakan skala likert, adapun pada alat ukur tersebut diberikan 4 alternatif jawaban, yaitu sangat paham, paham, tidak paham, dan sangat tidak paham, dimana nilai masing - masing jenis item memiliki angka yang berbeda (Sugiyono, 2018).

Kuisioner ini berskala ordinal, yaitu skala yang tidak hanya mengklasifikasi subjek menurut persamaan atau kategori tetapi juga mengurut subjek dalam urutan atau tingkatan (Silalahi, 2012).

Tabel 2 Sistem Penilaian Alat Ukur Pemahaman Sistem Rujukan Berjenjang

\begin{tabular}{lll}
\hline Pilihan Jawaban & Item Positif $(+)$ & Item Negative $(-)$ \\
\hline Sangat Paham & 4 & 1 \\
\hline Paham & 3 & 2 \\
\hline Tidak Paham & 2 & 3 \\
\hline Sangat Tidak Paham & 1 & 4 \\
\hline
\end{tabular}

Secara umum validitas mengukur apa yang hendak diukur atau sejauh mana perbedaan dalam skor pada suatu instrument item-item yang diukur dan kategori respon yang diberikan kepada suatu variabel khusus mencerminkan kebenaran perbedaan antara individu, kelompok, atau situasi dalam karakteristik (variabel) yang dikemukakan untuk ukuran (Silalahi, 2012). Penghitungan reabilitas alat ukur ini dengan rumus Alpha Cronbach yaitu menggunakan kriteria yang dikemukakan oleh Dancey \& Reidy (2011):

Tabel 3 Kriteria Koefisien menurut Dancey \& Reidy (2011)

\begin{tabular}{cc}
\hline 0 & Zero \\
\hline $0,1-0,3$ & Weak \\
\hline $0,4-0,6$ & Moderate \\
\hline $0,7-0,9$ & Strong \\
\hline 1,00 & Perfect \\
\hline
\end{tabular}

Langkah-langkah perhitungan menggunakan SPSS 20.0

1. Memasukan angka-angka hasil kuesioner/data mentah yang telah dijawab oleh responden pada Microsoft excel 
2. Membuka program SPSS 20.0 for windows, dan memindahkan angka-angka tersebut pada data view

3. Klik variable view, mengganti angka desimal dan memilih data ordinal pada kolom measure

4. Klik analyze, kemudian pilih scale dan kemudian membuka reability analysis, maka akan timbul bagan reability analysis

Pilih rumus alpha Cronbach pada kolom model, kemudian klik OK

Metode analisa data yang digunakan dalam penelitian ini adalah metode analisa data deskriptif yang bertujuan untuk mengetahui status dan menggambarkan fenomena berdasarkan data yang terkumpul. Pada analisa statistik, peneliti menggunakan analisa statistik deskriptif, dengan menggunakan analisa univarian, yang mana teknik analisa dilakukan dengan frequency distributions.

\section{Hasil dan Pembahasan}

Dalam penelitian yang dilakukan, diperoleh data dari Jumlah populasi adalah 136 pasien dan tingkat kesalahan atau margin of error yang dikehendaki adalah $10 \%$. Sampel penelitian yang akan diteliti sebanyak 58 pasien yang dirujuk di puskesmas Parongpong. Penelitian diperoleh melalui alat ukur Pemahaman Sistem Rujukan Berjenjang, pada alat ukur tersebut memiliki 6 indikator yaitu Interpreting (Interpretasi), Exemplifying (Memberikan Contoh), Clasification (Klasifikasi), Infering (Menyimpulkan), Comparing (Membandingkan), Dan Explaining (Menjelaskan).

\section{Uji Validitas}

Uji validitas yang dilakukan dengan menggunakan korelasi: jika $r$ hitung $>\mathrm{r}$ tabel maka pernyataan tersebut dikatakan valid, sedangkan jika $r$ hitung $<r$ tabel maka pernyataan tersebut dianggap tidak valid. Dalam penelitian ini sampel yang diambil sebanyak 58 responden, maka didapatkan nilai $r$ tabel dengan taraf sinifikan 5\% atau 0,05 sebesar 0,254 .

Tabel 4 Hasil Uji Validitas

\begin{tabular}{cccc}
\hline \multirow{2}{*}{ PERNYATAAN } & \multicolumn{2}{c}{ VALIDITAS } & \multirow{2}{*}{ KETERANGAN } \\
\cline { 2 - 3 } & r-hitung & r-tabel & \\
\hline 1 & 0.761 & 0.254 & Valid \\
\hline 2 & 0.497 & 0.254 & Valid \\
\hline 3 & 0.712 & 0.254 & Valid \\
\hline 4 & 0.771 & 0.254 & Valid \\
\hline 5 & 0.766 & 0.254 & Valid \\
\hline 6 & 0.797 & 0.254 & Valid \\
\hline 7 & 0.808 & 0.254 & Valid \\
\hline 8 & 0.715 & 0.254 & Valid \\
\hline 9 & 0.784 & 0.254 & Valid \\
\hline 10 & 0.487 & 0.254 & Valid
\end{tabular}




\begin{tabular}{llll}
11 & 0.801 & 0.254 & Valid \\
\hline 12 & 0.816 & 0.254 & Valid \\
\hline 13 & 0.814 & 0.254 & Valid \\
\hline 14 & 0.832 & 0.254 & Valid \\
\hline
\end{tabular}

Sumber: Output SPSS 20.0

Berdasarkan tabel di atas dapat disimpulkan hasil pengujian validitas untuk alat ukur pemahaman rujukan berjenjang menunjukan bahwa seluruh item sebanyak 14 pernyataan dinyatakan valid dimana nilai $r$ hitung $>\mathrm{r}$ tabel.

\section{Uji Reabilitas}

Dengan hasil reabilitas yang diperoleh dari pengujian alat ukur ini dengan nilai cronbach's alpha sebesar $0.936>0.6$ sehingga dapat dikatakan reliabel

Table 5 Hasil Reliabilitas Alat Ukur Pemahaman Sistem Rujukan Berjenjang

Reliability Statistics

\begin{tabular}{l}
$\begin{array}{l}\text { Cronbach's } \\
\text { Alpha }\end{array}$ \\
\hline $.936 \quad 14$ \\
\hline Sumber: Output SPSS 20.0
\end{tabular}

Berikut hasil pengolahan data dilihat dari setiap indikator:

Tabel 6 Kategori Pemahaman Sistem Rujukan Berjenjang Pada Setiap Indikator

\begin{tabular}{|c|c|c|c|c|c|}
\hline & & & Pemah & $\begin{array}{l}\text { n Sisten } \\
\text { erjenjan }\end{array}$ & ukan \\
\hline & & & Presentase & Paham & $\begin{array}{l}\text { Tidak } \\
\text { Paham }\end{array}$ \\
\hline & $I$ & Paham & $83 \%$ & 48 & \\
\hline & Hoverpreng & Tidak Paham & $17 \%$ & & 10 \\
\hline & $\Gamma_{0}+\rho_{0}$ & Paham & $43 \%$ & 25 & \\
\hline & Lxempiyying & Tidak Paham & $57 \%$ & & 33 \\
\hline & $C+C_{0}$ & Paham & $90 \%$ & 52 & \\
\hline 鶯 & costgicaiton & Tidak Paham & $10 \%$ & & 6 \\
\hline $\bar{\Xi}$ & Jnforing & Paham & $47 \%$ & 27 & \\
\hline & injering & Tidak Paham & $53 \%$ & & 31 \\
\hline & . & Paham & $45 \%$ & 26 & \\
\hline & Comparing & Tidak Paham & $55 \%$ & & 32 \\
\hline & & Paham & $43 \%$ & 25 & \\
\hline & Expla & Tidak Paham & $57 \%$ & & 33 \\
\hline
\end{tabular}

Penelitian ini dilakukan kepada 58 pasien rujukan berjenjang di puskesmas Parongpong. Penelitian ini diperoleh melalui alat ukur pemahaman sistem rujukan 
berjenjang. Menurut Benjamin S Bloom pemahaman (comprehension) adalah sebuah kemampuan seseorang untuk mengerti atau memahami sesuatu setelah sesuatu tersebut diketahui atau diingat. Secara umum pemahaman yang dipahami oleh para pasien dalam melaksanakan rujukan berjenjang dibagi menjadi dua kategori yaitu paham dan tidak paham. Anderson (2002) dalam revisi Bloom mengungkapkan bahwa yang termasuk dalam pemahaman ini meliputi seluruh indikator yaitu Interpreting (Interpretasi), Exemplifying (Memberikan Contoh), Clasification (Klasifikasi), Infering (Menyimpulkan), Comparing (Membandingkan), Dan Explaining (Menjelaskan) dinyatakan paham.

Berdasarkan tabel 6 diketahui bahwa sebagian besar pasien rujukan berjenjang puskesmas Parongpong kurang dalam pemahaman atau ketidak-pahaman pasien terhadap sistem rujukan berjenjang yang ditandai dari empat indikator yang dikategorikan tidak paham. Ketidakpahaman yang merujuk pada sistem rujukan berjenjang yang merupakan program jaminan kesehatan nasional yang termasuk pada pelayanan kesehatan pencarian bantuan kepada fasilitas kesehatan yang lebih baik atau memiliki sumber daya tertentu baik vertikal atau horizontal ini dengan menelaah setiap item serta indikator pernyataan yang diberikan dari alur hingga rujukan rumah sakit yang dituju.

Setiap pasien yang berada pada kategori tidak paham ini cenderung selalu menanyakan atau membantah apabila rujukan yang dituju berbeda dengan yang diinginkannya sebagai contoh pasien tersebut memiliki penyakit yang bisa ditangani oleh rumah sakit tipe $\mathrm{C}$ dan $\mathrm{D}$ tetapi karena pasien merasa rumahnya lebih dekat dengan rumah sakit tipe $\mathrm{B}$, pasien menginginkan dirujuk kerumah sakit tersebut, hal ini tidak akan bisa terjadi karena segala rujukan akan dipilihkan oleh aplikasi BPJS yaitu Pcare. Akibat dari pemahaman yang kurang inilah pasien meminta hal tersebut.

\section{Analisis Indikator Interpreting (Interpretasi) Terhadap Prosedur Rujukan Berjenjang}

Diuraikan bahwa hasil data dengan 4 item pertanyaan tabel 6 diketahui pada indikator pertama yaitu Interpreting (interpretasi) adalah menerjamahkan, menguraikan kata-kata, menggambarkan dan mengklarifikasikan suatu materi tertentu, yang memiliki 4 item atau pernyataan yang lebih kepada pengenalan bahwa sebuah rujukan berjenjang, rujukan bisa dilakukan kapan saja diatur oleh Jaminan Kesehatan Nasional, kemudian syarat syarat yang diperlukan maka dari itu 48 pasien dari sampel yang sebanyak 58 pasien merasa paham akan hal tersebut.

\section{Analisis Indikator Exemplifying (Memberikan Contoh) Terhadap Syarat Rujukan Berjenjang}

Dengan hasil data berisi 3 item pernyataan Bila dikaji melalui data perindikator pada data tabel 6 diketahui pada indikator kedua yaitu exemplifying yang merupakan kemampuan pada diri seseorang untuk memberikan contoh suatu konsep yang sudah dipelajari, terlihat bahwa yang memiliki data tidak paham lebih tinggi. Pada rujukan berjenjang ini sebanyak 33 pasien tidak mengetahui alur serta tipe rumah sakit apa yang bisa menangani penyakit dari pasien tersebut. 


\section{Analisis Indikator Classification (Klasifikasi) Terhadap Prosedur Rujukan Berjenjang}

Berdasarkan tabel 6 yang menggunakan 3 item pernyataan indikator klasifikasi sebanyak 52 pasien paham akan pernyataan yang diajukan yaitu pasien dapat melakukan rujukan di puskesmas parongpong bilamana kartu BPJS menunjukan fasilitas kesehatan Puskesmas Parongpong dan 39 pasien paham bilamana memerlukan rujukan, pasien tersebut harus kembali puskesmas parongpong. serta 15 pasien mengetahui fasilitas tingkat lanjutan dari puskesmas Parongpong adalah Rs. Lembang dan Rs. Mitra kasih.

Analisis Indikator Infering (Menyimpulkan) Terhadap Syarat Rujukan Berjenjang

Memperlihatkan hasil data dengan 2 item pernyataan pada pasien rujukan berjenjang puskesmas Parongpong, dengan kategori paham terdapat $47 \%$ pasien dan 53\% pasien dengan kategori tidak paham, dan dapat disimpulkan bahwa sebagian besar pasien rujukan berjenjang puskesmas Parongpong dapat teridentifikasikan indikator infering dalaam kategori tidak paham seperti pengguna Jaminan Kesehatan Nasional memiliki berbagai macam tipe keanggotaan kartu yaitu PBI (Penerima Bantuan Iuran) dan NonPBI, kemudian pada pendaftaran menunjukan identitas seperti KTP/KK.

Analisis Indikator Comparing (Membandingkan) Terhadap Syarat Dan Prosedur Rujukan Berjenjang

Dengan hasil data yang memiliki 1 item pernyataan pada pasien rujukan berjenjang puskesmas Parongpong, dengan kategori paham terdapat $45 \%$ pasien dan $55 \%$ pasien dengan kategori tidak paham, dan dapat disimpulkan bahwa sebagian besar pasien rujukan berjenjang puskesmas Parongpong dapat teridentifikasikan indikator comparing dalam kategori tidak paham.

\section{Analisis Indikator Explaining (Menjelaskan) Terhadap Prosedur Rujukan Berjenjang}

Memperlihatkan hasil data pada pasien rujukan berjenjang puskesmas Parongpong. Pada tabel ini membahas tentang bagaimana seorang pasien dapat menjelaskan atau paham mengenai pejelasan yang sudah disediakan dalam pernyataan kuesioner atau angket yang menjurus pada prosedur dari rujukan berjenjang itu sendiri dengan kategori paham terdapat $43 \%$ pasien dan $57 \%$ pasien dengan kategori tidak paham pada kemampuan mengembangkan atau menguraikan prosedur pada sistem rujukan berjenjang kepada pasien lainnya.dan dapat disimpulkan bahwa sebagian besar pasien rujukan berjenjang puskesmas Parongpong dapat teridentifikasikan indikator Explaining dalam kategori tidak paham.

Merujuk pada teori yang di kemukakan oleh Anderson \& Krathwohl pada tahun 2002 bahwa pemahaman harus meliputi enam kategori interpreting, exeplifying, clasifications, infering, comparing, dan explaning. Dengan demikian pemahaman pasien pada sistem rujukan berjenjang di Puskesmas Parongpong cenderung kurang dikarenakan hanya ada dua kategori yang terpenuhi.

Dari uraian di atas kendala yang mempengaruhi pelaksanaan sistem rujukan berjenjang di Puskesmas Parongpong terdapat pada pemahaman pasien itu sendiri dari mulai alur prosedur, manfaat, membandingkan rujukan berjenjang serta penggunaan 
kartu BPJS yang tergolong pada faskes Parongpong. Selain itu pemaparan sistem rujukan berjenjang hanya dilakukan bilamana seorang pasien sudah menanyakannya, dan pada pasien sendiri yang sudah lanjut usia serta pendidikan yang kurang. Kendala juga dirasakan bila seorang pasien baru pertama kali melakukan rujukan berjenjang ini.

Dengan kendala yang sudah dipaparkan diatas solusi yang dapat dilakukan untuk mengurangi hal tersebut adalah sebuah promosi kesehatan yang menyeluruh oleh petugas kesehatan.

Promosi kesehatan merupakan suatu proses yang bertujuan memungkinkan individu meningkatkan kontrol terhadap kesehatan dan meningkatkan kesehatannya dengan jelas mengenai pemberdayaan diri sendiri. Proses pemberdayaan tersebut dilakukan dari, oleh, untuk dan bersama masyarakat serta sesuai dengan sosial budaya setempat. Demi mencapai derajat kesehatan yang sempurna, baik dari fisik, mental maupun sosial, masyarakat harus mampu mengenal dan mewujudkan aspirasi dan kebutuhannya, serta mampu mengubah atau mengatasi lingkungannya (Kemenkes, 2007).

Promosi kesehatan yang peneliti maksud mengingat dari petugas kesehatan yang ada dan tentunya mengurangi kerumunan pada tempat pelayanan itu sendiri adalah pembuatan pamflet tentang alur serta prosedur, yang dilakukan dengan jelas serta efektif agar setiap pasien bisa melihat pamflet tersebut kemudian bisa mengaplikasikannya pada pelaksanaan sistem rujukan berjenjang.

\section{Kesimpulan}

Berdasarkan hasil (pengumpulan dan pengolahan) serta pembahasan berupa analisis data dengan judul Analisis pemahaman pasien terhadap sistem rujukan berjenjang peserta jaminan Kesehatan nasional (JKN) di puskesmas parongpong. Maka dapat diambil beberapa kesimpulan sebagai berikut:

1. Adanya ketidakpahaman pasien terhadap sistem rujukan berjenjang Jaminan Kesehatan Nasional dengan hasil penelitian pemahaman pasien empat dari enam indikator dinyatakan tidak paham, hal ini biasanya ditandai dengan pasien cenderung selalu menanyakan atau membantah apabila rujukan yang diberikan berbeda dengan yang diinginkannya

2. Pemahaman pasien sendiri merupakan kendala pelaksanaan sistem rujukan berjenjang dari mulai alur, prosedur, manfaat, membandikan rujukan berjenjang. Seperti pada FKTP yang terlampir dikartu seharusnya hanya puskesmas parongpong, pendidikan yang kurang, pasien yang sudah lanjut usia, dan pasien yang pertama kali melakukan rujukan.

3. Dengan kendala yang telah dipaparkan, solusi yang diambil oleh peneliti adalah melakukan promosi kesehatan dengan pembuatan pamflet tentang alur serta prosedur, yang dilakukan dengan jelas serta efektif agar setiap pasien bisa melihat pamflet tersebut kemudian bisa mengaplikasikannya pada pelaksanaan sistem rujukan berjenjang. 
Pustaka yang berupa judul buku

\section{Bibliografi}

Anderson, L. W., \& Krathwohl, D. (2002). A Taxonomy for Learning, Teaching, and Assesing. A Revision of Bloom's Taxonomy of Eductional Objectives. New York: Addison Wesley Longman, Inc.

Bloom, B. S. (2002). Taxonomy Of Educational Objectives. New York: Longmans.

Neuman, L. W. (2013). Metode Penelitian Sosial: Pendekatan Kualitatif dan Kuantitatif. Jakarta Barat: PT Indeks.

Silalahi, U. (2012). Metodelogi Penelitian Sosial. Bandung: PT Refika Aditama.

Sugiyono. (2018). Metode Penelitian Kuantitatif, Kualitatif, dan R\&D. Bandung: ALFABETA.

Sujanto, A. (2014). Psikologi Kepribadian. Jakarta: Penerbit Bumi Aksara.

\section{Pustaka yang berupa jurnal ilmiah}

Faulina, A. C., Khoiri, A., \& Herawati, Y. T. (2016). Kajian Pelaksanaan Sistem Rujukan Berjenjang Dalam Program Jaminan Kesehatan Nasional (Jkn) Di Upt. Pelayanan Kesehatan Universitas Jember. Jurnal Ilmu Kesehatan Masyarakat (IKESMA) Vol $12,93$.

Michael, M. (2018). Reviving the Functionality of the Referral Sistem in Uganda. Retrieved March 9, 2019, from https://www.udn.or.ug/udnmedia/news/147-reviving-the-functionality-of-the-referral-sistem-inuganda.html

Setiawati, M. E., \& Nurrizka, R. H. (2019). Evaluasi Pelaksanaan Sistem Rujukan Berjenjang Dalam Program Jaminan Kasehatan Nasional. Jurnal Kebijakan Kesehatan Indonesia (Jkki) VOL 08, 35-40.

\section{Pustaka yang berupa Prosiding Seminar:}

Muchsam, Y., \& Mareta, F. (2019). Analisis Pengaruh Kepahaman Sistem Rujukan Online peserta BPJS Terhadap Kepuasan Pelayanan BPJS. Seminar Nasional Informatika Medis (SNIMed), 34-39.

\section{Dokumen Hukum}

BPJS Kesehatan,2014. Peraturan Badan Penyelenggaran Jaminan Sosial Kesehatan Nomor 1 Tahun 2014 Tentang Penyelenggaran Jaminan Kesehatan. s.1.:BPJS Kesehatan.

Kementerian Kesehatan RI. Keputusan Menteri Kesehatan Republik Indonesia Nomor 585 tentang Pedoman Pelaksanaan Promosi Kesehatan di Puskesmas. In: Promosi Kesehatan, editor. Jakarta: Kemenkes RI,; 2007.

Kementerian Kesehatan RI. 2012. Peraturan Menteri Kesehatan Nomor 001 Tahun 2012 tentang Sistem Rujukan Pelayanan Kesehatan Perorangan. Jakarta 